\title{
Loan Pricing under Basel Capital Requirements*
}

\author{
Rafael Repullo \\ Javier Suarez \\ CEMFI and CEPR \\ CEMFI and CEPR
}

July 2004

* We would like to thank Patrick Bolton, Xavier Freixas, Luc Laeven, Guillaume Plantin, Ned Prescott, Jesús Saurina, Carlos Trucharte, and an anonymous referee for their comments, and Aitor Lacuesta for his research assistance. We also thank seminar participants at Delta, Mannheim, the Bank of England, the European Central Bank, the Federal Reserve Board, the Riksbank, the 2003 European Meeting of the Econometric Society, the CEPR/CREI/JFI Conference on Financial Structure and Monetary Policy Channels, and the NYU Conference on Recent Advances in Credit Risk Research. Financial support from the Spanish Ministry of Science and Technology (Grant No. BEC2002-03034) is gratefully acknowledged.

Address for correspondence: CEMFI, Casado del Alisal 5, 28014 Madrid, Spain. Tel: 34-914290551. Fax: 34-914291056. E-mail: repullo@cemfi.es, suarez@cemfi.es. 


\begin{abstract}
We analyze the loan pricing implications of the reform of bank capital regulation known as Basel II. We consider a perfectly competitive market for business loans where, as in the model underlying the internal ratings based (IRB) approach of Basel II, a single risk factor explains the correlation in defaults across firms. Our loan pricing equation implies that low risk firms will achieve reductions in their loan rates by borrowing from banks adopting the IRB approach, while high risk firms will avoid increases in their loan rates by borrowing from banks that adopt the less risk-sensitive standardized approach of Basel II. We also show that only a very high social cost of bank failure might justify the proposed IRB capital charges, partly because the net interest income from performing loans is not counted as a buffer against credit losses. A net interest income correction for IRB capital requirements is proposed.
\end{abstract}

Keywords: Bank regulation, capital requirements, credit risk, internal ratings, loan interest rates, loan defaults, net interest income.

JEL Classification: G21, G28, E43 


\section{Introduction}

The Basle Accord of 1988 consolidated capital requirements as the cornerstone of bank regulation. It required banks to hold a minimum overall capital equal to $8 \%$ of their risk-weighted assets. As all business loans were included in the full weight category, $8 \%$ became the universal capital charge for corporate lending. Following widespread criticism about the risk-insensitiveness of these requirements, as well as recent advances in risk measurement, the Basel Committee on Banking Supervision (BCBS) has recently approved a reform, known as Basel II, whose primary goal is "to arrive at significantly more risk-sensitive capital requirements" (BCBS, 2004, p. 2).

Basel II introduces a menu of approaches for determining capital requirements. ${ }^{1}$ The standardized approach contemplates the use of external ratings to refine the risk weights of the 1988 Accord (henceforth, Basel I), but leaves the capital charges for loans to unrated companies essentially unchanged. The internal ratings based (IRB) approach allows banks to compute the capital charges for each exposure from their own estimate of the probability of default (PD) and, possibly, the loss given default $(\mathrm{LGD}) .^{2}$

This paper provides an analysis of this reform along the lines that would first come to the mind of an economist or a financial analyst: How will the new rules alter the pricing of bank loans? How will the effects be distributed across credit risk categories? Will banks be safer under the new regulation? Does the new regulation reasonably trade off the benefits and costs of capital requirements?

We address these questions in the context of a perfectly competitive market for business loans. Importantly, we assume that loan default rates and, thus, banks'

\footnotetext{
${ }^{1}$ The exact implementation of the new agreement may vary across countries. Some countries may choose just one of the approaches, while others may leave the choice to the banks, subject to supervisory approval. Some countries may impose the new capital regulation to the whole universe of banks, while others may apply the new rules to their internationally active banks only; see Ferguson (2003) for a discussion of US plans in this respect.

${ }^{2}$ Specifically, two variants of the IRB approach are proposed. In the foundation IRB banks provide an estimate of the PD of each borrower and a formula gives the corresponding capital charge. In the advanced IRB, banks also input their own estimate of the LGD.
} 
credit losses are determined by the same single risk factor model that is used for the computation of capital charges in the IRB approach of Basel II. ${ }^{3}$ Banks have zero intermediation costs, are funded with fully insured deposits and equity capital, and supply loans to a large number of unrated firms with risky investment projects. Although bank shareholders are risk neutral, the cost of capital is assumed to be greater than the cost of deposits. ${ }^{4}$ A single factor of systematic risk explains the correlation in defaults across firms and, hence, the proportion of bank loans that default and the probability of bank failure. By limited liability, the final payoff of a bank's shareholders is equal to the bank's net worth (gross loan returns minus gross deposit liabilities) if it is positive, and zero otherwise. The competitive equilibrium interest rate for each class of loans is determined by a zero net (marginal) value condition that makes each loan's contribution to the expected discounted value of shareholders' final payoff equal to the initial equity contribution that the loan requires.

There are a number of reasons to argue that our setup constitutes an adequate benchmark with which to start. The assumption of perfect competition allows us to abstract from the important but rather tangential discussion on what model of imperfect competition is most reasonable in banking. Also it allows us to make the best case for capital requirements, since banks with market power get rents that provide a buffer against failure and, in a multiperiod setting, may give banks an additional incentive to remain solvent. ${ }^{5}$ By examining an economy that conforms to the single risk factor model embedded in the new regulation, we give this regulation the best chance to demonstrate its internal consistency. Finally, this model is good for tractability, yielding simple closed-form solutions for the distribution of credit losses.

\footnotetext{
${ }^{3}$ As shown by Gordy (2003), this is the only model for which the contribution of a given asset to value-at-risk (and hence the corresponding capital charge) is portfolio-invariant, that is, depends on the asset's own characteristics and not on those of the portfolio in which it is included.

${ }^{4}$ This can be rationalized by reference to explicit agency problems as in Holmström and Tirole (1997) or Diamond and Rajan (2000). The same assumption is made by Bolton and Freixas (2000), and Hellmann, Murdock and Stiglitz (2000), among others.

${ }^{5}$ In contrast, under perfect competition there are no such rents, so focusing on a static model implies no loss of generality in this dimension. Of course, in this setup we cannot capture frictions that are dynamic in nature, such as costs of issuing equity following the accumulation of credit losses. Modeling these frictions seems a natural next step in the analysis.
} 
Unlike in models where the distribution of the returns of bank assets has an unbounded support, ${ }^{6}$ in our setting the support is realistically bounded above by the principal and interest payments established in loan contracts. Moreover, the variability of the returns comes from credit losses that can be directly related to the $\mathrm{PD}$, the LGD, and the exposure to systematic risk of the corresponding loans. Thus, our loan pricing equation allows us to derive analytically the dependence of equilibrium loan rates on these parameters as well as on the capital requirement and the cost of bank capital.

These results are used to assess the qualitative and quantitative implications of the move from Basel I to Basel II. We predict that low risk firms will concentrate their borrowing in banks that adopt the IRB approach and will enjoy lower loan rates. This follows immediately from the fact that, for these firms, the IRB capital charges are lower than both the $8 \%$ of Basel I and the constant charge for loans to unrated companies of the standardized approach of Basel II. In contrast, high risk firms may find more attractive loan rates at the banks that adopt the standardized approach (or remain under the Basel I regime), in which case their interest rates will not change relative to the current situation. At the quantitative level, our simulations (based on a cost of bank capital of $10 \%$ per annum over the risk free rate) show that adopting the IRB approach may imply a reduction in loan rates (relative to Basel I) of 65 basis points for loans with a PD of $0.10 \%$, and an increase of about 125 basis points for loans with a PD of $10 \%$.

Under the IRB approach, banks' probabilities of failure are extremely low, with the lowest probabilities corresponding to the banks whose lending is concentrated in high risk loans. The reason for this is that, on top of their capital buffer, these banks enjoy a greater net interest income buffer which is not credited for when the capital requirement is computed, but clearly reduces the probability of failure. To address this issue, we derive a closed-form solution for a corrected IRB capital requirement

\footnotetext{
${ }^{6}$ For example, the geometric brownian motion process in Merton (1977), the normal distribution in Rochet (1992), and the lognormal distribution in Marshall and Prescott (2001).
} 
that takes into account the net interest income earned on performing loans. This correction leads to a reduction in the IRB capital requirements of almost 1 percentage point for a $\mathrm{PD}$ of $1 \%$ and almost 4 percentage points for a $\mathrm{PD}$ of $10 \%$.

Our simulations also show that, under the IRB approach, the probabilities of bank failure are so low that the equilibrium rates for each class of loans are very close to the corresponding actuarially fair rates. In other words, the easy-to-compute rate that equates the expected payments of a loan to its weighted marginal funding cost (from deposits and capital, depending on how much of the latter is required by regulation) provides a precise approximation to the solution of our pricing equations.

We also examine whether the cost of the IRB capital requirements of Basel II can be justified in terms of a reduction in the social cost of bank failures. We construct a social welfare function by adding the expected payoffs of the four types of agents in the economy: entrepreneurs, bank shareholders, depositors, and the government. For simplicity, the government bears the deposit insurance payouts as well as an additional social cost of bank failure, which we assume proportional to the initial assets of the failed banks. Our welfare measure turns out to be equal to the expected net return of firms' investment projects minus the cost of the capital required for providing their loans and the corresponding expected social cost of bank failure. We characterize the socially optimal capital requirement for banks specialized in different classes of loans, and then we ask for what level of the social cost of bank failure the charges of the IRB approach would be optimal. We show that this cost is remarkably increasing in the $\mathrm{PD}$, reaching implausibly high values for high $\mathrm{PD}$ loans. This suggests that the IRB charges are too high, especially for high risk loans. We briefly discuss possible causes for this apparent flaw in the new regulation and show that our proposed net interest income correction would partly alleviate the problem.

Finally, we use our model to discuss two related important issues. First, we study the implications of Basel II for the volume of bank lending, which required us to extend the model by incorporating interest-rate-sensitive loan demands. With negatively sloped demand functions, all previously mentioned effects on loan rates would 
translate into opposite-sign effects on loan volumes. Second, we consider the case in which the cost of bank capital is determined by demand and supply considerations, a relevant situation for the discussions on the potential procyclicality of Basel II, that is on whether the greater risk-sensitivity of capital regulation might exacerbate business cycle fluctuations.

The paper is organized as follows. Section 2 presents the model. Section 3 derives the main results on equilibrium loan pricing. Section 4 uses these results to discuss the qualitative and quantitative implications of the transition from Basel I to Basel II, and derives a net interest income correction for the IRB requirements. Section 5 presents our welfare analysis of capital requirements. Section 6 comments on two possible extensions, and Section 6 offers some concluding remarks. Appendix A discusses the approximation of equilibrium rates by actuarially fair rates, Appendix B extends the analysis to the case of positive intermediation costs, and Appendix C contains the proofs of the results stated in the main text.

\section{The Model}

Consider a risk-neutral economy with two dates, $t=0,1$, and a single factor of systematic risk, $z \sim N(0,1)$. There is a continuum of measure of one of firms, indexed by $i$, and a large number of banks.

\section{$2.1 \quad$ Firms}

Each firm $i$ has a project that requires a unit of investment at $t=0$, and it is owned by a penniless entrepreneur who finances the required investment with a bank loan. At $t=1$ the project yields a gross return $1+a$ if it succeeds and $1-\lambda$ if it fails. The project is successful if and only if $x_{i} \leq 0$, where $x_{i}$ is a latent random variable defined by

$$
x_{i}=\mu_{i}+\sqrt{\rho} z+\sqrt{1-\rho} \varepsilon_{i},
$$


and $\varepsilon_{i} \sim N(0,1)$ is independently distributed across firms and independent of $z$. Parameter $\mu_{i} \in \mathbb{R}$ measures the financial vulnerability of firm $i$, while parameter $\rho \in[0,1]$ captures its exposure to the systematic risk factor. ${ }^{7}$

There are two observable classes of firms that differ in the value of the financial vulnerability parameter: low risk firms have $\mu_{i}=\mu_{l}$, and high risk firms have $\mu_{i}=\mu_{h}$, with $\mu_{l}<\mu_{h}$. With a slight abuse of notation, we will use the subscript $j=l, h$ to identify the variables that refer to the risk class of an individual firm $i$.

From (1) we have that the unconditional distribution of the latent variable $x_{i}$ is $N\left(\mu_{i}, 1\right)$, so the unconditional probability of default (PD) of firms of class $j$ is

$$
\bar{p}_{j}=\operatorname{Pr}\left(\mu_{j}+\sqrt{\rho} z+\sqrt{1-\rho} \varepsilon_{i}>0\right)=\Phi\left(\mu_{j}\right)
$$

where $\Phi$ denotes the cumulative distribution function of a standard normal random variable. Since $\mu_{l}<\mu_{h}$, low risk firms have a lower PD than high risk firms, that is, $\bar{p}_{l}<\bar{p}_{h}$.

From (1) we also have that the distribution of the latent variable $x_{i}$ conditional on the realization of the systematic risk factor $z$ is $N\left(\mu_{i}+\sqrt{\rho} z, 1-\rho\right)$, so the conditional probability of default or default rate of firms of class $j$ is

$$
p_{j}(z)=\operatorname{Pr}\left(\mu_{j}+\sqrt{\rho} z+\sqrt{1-\rho} \varepsilon_{i}>0 \mid z\right)=\Phi\left(\frac{\Phi^{-1}\left(\bar{p}_{j}\right)+\sqrt{\rho} z}{\sqrt{1-\rho}}\right)
$$

where we have used (2) to write the financial vulnerability parameter $\mu_{j}$ as a simple non-linear transformation of the $\mathrm{PD}, \Phi^{-1}\left(\bar{p}_{j}\right)$. Hence the default rate $p_{j}(z)$ is increasing in the $\mathrm{PD} \bar{p}_{j}$ and in the realization of the systematic risk factor $z$.

To lighten the notation, in some of the derivations below we will use $p_{j}=p_{j}(z)$ to denote the default rate of the firms of class $j$. The cumulative distribution function of $p_{j}$ is given by

$$
F_{j}\left(p_{j}\right)=\operatorname{Pr}\left(p_{j}(z) \leq p_{j}\right)=\Phi\left(\frac{\sqrt{1-\rho} \Phi^{-1}\left(p_{j}\right)-\Phi^{-1}\left(\bar{p}_{j}\right)}{\sqrt{\rho}}\right),
$$

\footnotetext{
${ }^{7}$ Notice that $\rho$ is also the correlation between the latent variables that determine the success or failure of any two firms.
} 
where we have used (3) and the fact that $z$ is a standard normal random variable. Obviously, the mean of the distribution of the default rate $p_{j}$ is the $\mathrm{PD}$ of the corresponding class of loans, $\bar{p}_{j}$, while the variance is entirely determined by (and increasing in) the exposure to systematic risk, $\rho{ }^{8}$

\subsection{Banks}

Loans to firms are supplied by perfectly competitive banks that are funded with deposits and equity capital, and for simplicity have zero intermediation costs. ${ }^{9}$ Bank deposits are insured by a government-funded deposit insurance scheme, and they are in perfectly elastic supply at an interest rate which is normalized to zero. ${ }^{10}$ Banks' equity capital is provided by a special class of agents, called bankers, who require an expected rate of return $\delta \geq 0$ on their investment. A strictly positive $\delta$ captures either the scarcity of bankers' wealth or, perhaps more realistically, the existence of a premium for the agency and/or asymmetric information problems faced by them. ${ }^{11}$

By limited liability, bankers receive at $t=1$ each bank's net worth (that is, gross loan returns minus gross deposit liabilities) if it is positive, and zero otherwise. Bankers maximize the expected value of this payoff discounted at the rate $\delta$ and net of their initial contribution of capital. Prudential regulation requires banks to hold some minimum equity capital, according to schemes that will be specified below.

Specifically, consider a bank with a loan portfolio of size one at $t=0$, and let

\footnotetext{
${ }^{8}$ Actually, the fact that $\partial F_{j}\left(p_{j}\right) / \partial \rho \geq 0$ if and only if $p_{j} \leq \Phi\left(\mu_{j} \sqrt{1-\rho}\right)$ implies that increasing $\rho$ produces a mean-preserving spread in the distribution of $p_{j}$.

${ }^{9}$ We relax this assumption in Appendix B.

${ }^{10}$ Introducing a positive, flat deposit insurance premium would increase the cost of deposits but if, realistically, they remain cheaper than banks' equity capital, this extra cost would be reflected in loan rates in an obvious way, without qualitatively altering any of our main results. Risk-sensitive premia would require a more careful analysis. If they were designed so as to be actuarially fair under any possible bank risk profile, our discussion below about the effects of bankers' limited liability would have to be modified. In essence, loan pricing would boil down to the actuarially fair loan rates defined in Eq. (13). But the quantitative implications obtained in Sections 4 and 5 would remain virtually unchanged since, at the levels of solvency induced by both Basel I and Basel II, the equilibrium loan rates that we compute happen to be almost identical to the actuarially fair rates.

${ }^{11}$ See Holmström and Tirole (1997) and Diamond and Rajan (2000) for explicit models of why $\delta$ might be positive.
} 
$\gamma \in[0,1]$ denote the proportion of its lending that is allocated to low risk firms. Since each firm's class is observable, the bank charges a loan rate $r_{l}$ to low risk firms and a loan rate $r_{h}$ to high risk firms. When a firm of class $j=l, h$ succeeds the bank gets $1+r_{j}$, while when it fails the bank gets $1-\lambda$, so parameter $\lambda$ measures the loss given default (LGD). ${ }^{12}$ If $k$ is the fraction of the bank's portfolio that is funded with equity capital, then the value of the bank's net worth at $t=1$ conditional on the realization of the systematic risk factor $z$ is

$$
\begin{aligned}
\pi(z)= & \gamma\left[\left(1-p_{l}(z)\right)\left(1+r_{l}\right)+p_{l}(z)(1-\lambda)\right] \\
& +(1-\gamma)\left[\left(1-p_{h}(z)\right)\left(1+r_{h}\right)+p_{h}(z)(1-\lambda)\right]-(1-k),
\end{aligned}
$$

where $p_{l}(z)$ and $p_{h}(z)$ are the default rates of low and high risk loans, respectively. ${ }^{13}$ The first term in (5) is the expected payment from low risk firms, the second term is the expected payment from high risk firms, and the third term is the amount owed to the depositors. The bank's objective is to maximize the expected discounted value of $\max \{\pi(z), 0\}$ net of bankers' initial infusion of capital, that is,

$$
V=-k+\frac{1}{1+\delta} E[\max \{\pi(z), 0\}]=-k+\frac{1}{1+\delta} \int_{-\infty}^{\widehat{z}} \pi(z) d \Phi(z),
$$

where $\widehat{z}$ denotes the critical value of $z$ for which $\pi(z)=0$ (or $\infty$, if $\pi(z)$ is positive for all $z)$.

From here it is immediate to show that

$$
\frac{\partial V}{\partial k}=-1+\frac{\Phi(\widehat{z})}{1+\delta}<0
$$

so the bank will hold the minimum possible amount of capital, which is the one required by regulation. ${ }^{14}$ Thus, from now onwards, $k$ will denote the minimum capital requirement.

\footnotetext{
${ }^{12}$ We are implicitly assuming that the firms' net success return $a$ is sufficiently large, so that $a>r_{j}$ for $j=l, h$.

${ }^{13}$ Notice that, by the law of large numbers, the default rate of each class of loans coincides with the actual proportion of those loans that default.

${ }^{14}$ Notice that, if $\widehat{z}<\infty$, then $\partial V / \partial k<0$ obtains even when $\delta=0$, that is, when bankers do not require a higher rate of return than depositors. This is due to the fact that deposits would still be a cheaper source of finance, since they are covered by deposit insurance in case of bank failure.
} 


\subsection{Basel capital requirements}

Under Basel I the capital requirement applicable to all business loans is $8 \%$ so $k$ is a constant. This is also the case for loans to unrated firms under the standardized approach of Basel II, while under the internal ratings based (IRB) approach of Basel II, bank capital must cover the losses due to loan defaults with a probability (or confidence level) $\alpha$. Specifically, for a bank that invests a proportion $\gamma$ of its portfolio on low risk loans and the rest on high risk loans, the IRB capital requirement has the additive form

$$
k(\gamma)=\gamma k_{l}+(1-\gamma) k_{h}
$$

where

$$
k_{j}=\lambda p_{j}\left(z_{\alpha}\right)=\lambda \Phi\left(\frac{\Phi^{-1}\left(\bar{p}_{j}\right)+\sqrt{\rho} \Phi^{-1}(\alpha)}{\sqrt{1-\rho}}\right) .
$$

In the last expression, $z_{\alpha}$ denotes the $\alpha$-quantile of the distribution of the systematic risk factor, that is, the value that satisfies $\Phi\left(z_{\alpha}\right)=\operatorname{Pr}\left(z \leq z_{\alpha}\right)=\alpha$, and the last equality is obtained from (3). By construction, $\operatorname{Pr}\left(p_{j} \leq p_{j}\left(z_{\alpha}\right)\right)=\alpha$. Hence, the IRB capital charge (8) for loans of class $j$ is the capital required to absorb the credit losses (per unit) of these loans with probability $\alpha .^{15}$

Maturity adjustments aside, Eq. (8) is the Basel II formula for the computation of the IRB capital requirement on loans with a PD $\bar{p}_{j}{ }^{16}$ Clearly, $\bar{p}_{l}<\bar{p}_{h}$ implies $k_{l}<k_{h}$, so the capital charge for low risk loans is smaller than the charge for high risk loans. The IRB requirement (8) is proportional to the LGD $\lambda$ and is increasing in the confidence level $\alpha$. Moreover, one can show that the derivative of $k_{j}$ with respect to parameter $\rho$ is positive whenever

$$
\Phi\left(\sqrt{\rho} \Phi^{-1}\left(\bar{p}_{j}\right)\right)>1-\alpha
$$

\footnotetext{
${ }^{15}$ Basel II establishes that the expected losses, $\lambda \bar{p}_{j}$, should be covered with general loan loss provisions, while the remaining charge, $\lambda p_{j}\left(z_{\alpha}\right)-\lambda \bar{p}_{j}$, should be covered with capital. From the perspective of our analysis, provisions are just another form of equity capital and thus the distinction between the expected and unexpected components of loan losses is immaterial.

${ }^{16}$ In the Basel II formula, the PD also determines the value to be imputed to the parameter $\rho$ of exposure to systematic risk. This is based on empirical studies (for example, Lopez, 2004) which suggest the existence of a negative relationship between PDs (typically larger for small and medium sized firms) and the exposure to the risk factor $z$ (typically smaller for those firms).
} 
a condition that is easily satisfied for high values of the confidence level $\alpha$.

Notice that the additive expression (7) for the capital requirement of a bank with a proportion $\gamma$ of low risk loans is trivially valid also under Basel I and the standardized approach of Basel II, which impose the same charges for low and high risk loans, $k_{l}=k_{h}$.

\section{$3 \quad$ Equilibrium loan pricing}

This section derives a loan pricing equation that characterizes the equilibrium interest rates for the different classes of loans. The analysis is simplified by the following specialization result which follows from the convexity in the banks' objective function implied by limited liability.

Lemma 1 With additive capital requirements and zero intermediation costs, it is optimal for banks to specialize in either high risk or low risk lending.

Intuitively, banks specialized in either high risk $(\gamma=0)$ or low risk lending $(\gamma=1)$ take advantage of limited liability whenever the systematic risk factor $z$ is high enough for such lending to yield negative net worth

$$
\pi_{j}(z)=\left(1-p_{j}(z)\right)\left(1+r_{j}\right)+p_{j}(z)(1-\lambda)-\left(1-k_{j}\right)=k_{j}+r_{j}-p_{j}(z)\left(\lambda+r_{j}\right)
$$

where $j=l, h$ denotes the loan class in which the bank specializes. In contrast, for a bank with a mixed loan portfolio $(0<\gamma<1)$, there will generally be a range of realizations of $z$ for which one of the loan classes makes a positive contribution to the bank's net worth, while the other makes a negative contribution. Clearly, bankers would prefer to hold each loan class as a separate corporate entity rather than netting the profits of the first class with the losses of the second.

With positive intermediation costs that imply some complementarity in the provision of the various classes of loans, the bank's portfolio problem may have an interior solution $(0<\gamma<1)$, but we show in Appendix B that our equilibrium analysis remains essentially unchanged. 


\subsection{Loan pricing equation}

Now, specializing the bank's objective function (6) to the case in which the bank specializes in loans of class $j$, and using (10) and the cumulative distribution function (4) of the default rate $p_{j}$, the net value of such bank can be written as

$$
V_{j}=-k_{j}+\frac{1}{1+\delta} \int_{0}^{\widehat{p}_{j}}\left[k_{j}+r_{j}-p_{j}\left(\lambda+r_{j}\right)\right] d F_{j}\left(p_{j}\right)
$$

where $\widehat{p}_{j}$ is the bankruptcy default rate defined by

$$
\widehat{p}_{j} \equiv \min \left\{\frac{k_{j}+r_{j}}{\lambda+r_{j}}, 1\right\} .
$$

To explain (12), notice that in the normal case where $k_{j}<\lambda$ the bankruptcy default rate is obtained by solving $\pi_{j}=k_{j}+r_{j}-\widehat{p}_{j}\left(\lambda+r_{j}\right)=0$, so $\widehat{p}_{j}<1$, while in the case where $k_{j} \geq \lambda$ the bank's capital covers the credit losses even when all its loans default, so we set $\widehat{p}_{j}=1$.

Under perfect competition, the equilibrium rate $r_{j}^{*}$ for loans of class $j$ is determined by the zero net value condition $V_{j}=0$. Otherwise, the market for this class of loans would not clear, since banks specialized in these loans would like either to infinitely expand their loan portfolio (if $V_{j}>0$ ) or not to lend at all (if $V_{j}<0$ ).

In the special case where the bank's capital covers the credit losses even when all its loans default $\left(k_{j} \geq \lambda\right)$, the bank's net value can be written as

$$
V_{j}=-k_{j}+\frac{1}{1+\delta}\left[k_{j}+r_{j}-\bar{p}_{j}\left(\lambda+r_{j}\right)\right]=\frac{1}{1+\delta}\left[\left(1-\bar{p}_{j}\right) r_{j}-\bar{p}_{j} \lambda-\delta k_{j}\right]
$$

Thus the net value of the bank equals the discounted value of the expected net income from its loan portfolio minus the opportunity cost of the required capital. In this case it is possible to explicitly solve the zero net value condition, $V_{j}=0$, which gives the actuarially fair rate

$$
\bar{r}_{j}=\frac{\bar{p}_{j} \lambda+\delta k_{j}}{1-\bar{p}_{j}} .
$$

This rate is also the one that would obtain if bankers had unlimited liability, or if depositors were not insured and demanded proper compensation for the losses in case of bank failure, or if the government charged actuarially fair deposit insurance premia. 


\subsection{Determinants of loan rates}

We discuss now the properties of the equilibrium loan rate $r_{j}^{*}$ under both Basel I (or the standardized approach of Basel II) and the IRB approach of Basel II, focussing on the realistic case $0<k_{j}<\lambda$. The following result refers to the first regulatory framework, where the capital requirement $k_{j}$ is constant across all classes of (unrated) corporate loans.

Proposition 1 Under Basel I (or the standardized approach of Basel II), the equilibrium loan rate $r_{j}^{*}$ satisfies $0<r_{j}^{*}<\bar{r}_{j}$ and is increasing in the capital requirement $k_{j}$, the $P D \bar{p}_{j}$, the $L G D \lambda$, and the cost of capital $\delta$, and decreasing in $\rho$.

Not surprisingly, $r_{j}^{*}$ increases with the PD and the LGD of the loan, which increase expected credit losses, as well as with the cost and the required level of capital. ${ }^{17}$ The effect of the exposure to systematic risk $\rho$ is somewhat more intriguing, but it is explained by the subsidization coming from the deposit insurance system, which is increasing in the variability of bank profits (which rises with $\rho$ ). Under perfect competition, the subsidy is passed on to firms in the form of cheaper loans.

Obviously, if the IRB capital requirement happens to coincide with the constant capital requirement of Basel I, then both regulatory regimes will lead to the same equilibrium loan rate $r_{j}^{*}$. However, under the IRB approach, the loans' PD and LGD, as well as the exposure to systematic risk $\rho$, have an indirect effect on loan pricing, via the capital requirement $k_{j}$, determined by (8). These indirect effects add to the (direct) effects described in Proposition 1 leading to the following result.

Proposition 2 Under the IRB approach of Basel II, the equilibrium loan rate $r_{j}^{*}$ is more sensitive to changes in the $P D \bar{p}_{j}$ and the $L G D \lambda$ than under an initially equivalent Basel I capital requirement. Moreover, if the confidence level $\alpha$ is sufficiently high, $r_{j}^{*}$ may be increasing in $\rho$.

\footnotetext{
${ }^{17}$ Interestingly, $k_{j}$ has a positive impact on $r_{j}^{*}$ even when $\delta=0$. This is because requiring capital reduces the subsidization of credit losses by the deposit insurance system.
} 
The indirect effects of the PD and LGD parameters reinforce their direct effects since both affect positively the capital requirement, which in turn affects positively the equilibrium loan rate. Changes in the exposure to systematic risk $\rho$ produce ambiguous effects on $r_{j}^{*}$, since for high values of the confidence level $\alpha$ (specifically, when (9) holds), the IRB requirement is increasing in $\rho$. Indeed, numerical simulations show that, for realistic parameter values, the positive indirect effect dominates the negative direct effect.

\section{Implications of Basel II}

This section uses the analytical framework developed above to discuss the qualitative and quantitative effects of the adoption of the Basel II reform of bank capital regulation. In view of some of the results, we develop a net interest income correction for the IRB capital requirements.

\subsection{Qualitative effects}

As we have already pointed out, Basel I established a common capital requirement for all business loans, $k^{\mathrm{I}}=8 \%$, while Basel II allows banks to choose between the standardized approach, in which all loans to unrated firms carry a constant capital charge, $k^{\mathrm{S}}$, and the IRB approach under which each class of loans $j$ carries a different capital charge, $k_{j}^{\mathrm{IRB}}$, computed using (8). Clearly, our previous results imply that the equilibrium interest rate for each class of loans will be determined by the approach for which the capital charge is the lowest.

For the purposes of illustration, we focus on unrated uncollateralized corporate loans for which the capital charge of the standardized approach of Basel II equals that of Basel I, that is, $k^{\mathrm{S}}=k^{\mathrm{I}}=8 \%$. Hence, if all banks were to adopt the standardized approach, moving from Basel I to Basel II would produce no change in equilibrium loan rates.

On the other hand, for any given values of the $\operatorname{LGD} \lambda$, the exposure to systematic 
risk $\rho$, and the confidence level $\alpha$, one can identify a unique PD

$$
\bar{p}^{\mathrm{S}}=\Phi\left(\sqrt{1-\rho} \Phi^{-1}\left(k^{\mathrm{S}} / \lambda\right)-\sqrt{\rho} \Phi^{-1}(\alpha)\right)
$$

such that the IRB formula (8) yields a capital charge equal to $k^{\mathrm{S}}$. Then, assuming that the PDs of our low risk and high risk loans fall respectively below and above such threshold, $\bar{p}_{l}<\bar{p}^{\mathrm{S}}<\bar{p}_{h}$, we have

$$
k_{l}^{\mathrm{IRB}}<k^{\mathrm{S}}<k_{h}^{\mathrm{IRB}} .
$$

Hence banks adopting the IRB (standardized) approach of Basel II would be able to offer better rates to low risk (high risk) firms than banks adopting the standardized (IRB) approach. This allows us to state the following result.

Proposition 3 Under Basel II, the equilibrium rates of low risk loans will be determined by the capital charges of the IRB approach and will be lower than under Basel I, while the equilibrium rates of high risk loans will be determined by the capital charges of the standardized approach and will be same as under Basel I.

This result is due to the advantageous (disadvantageous) treatment that low risk (high risk) lending receives in the IRB approach relative to Basel I (and the standardized approach of Basel II for unrated corporate loans). The implication under specialization is that banks that lend to low risk firms will adopt the IRB approach, while banks that lend to high risk firms will adopt the standardized approach. ${ }^{18}$

The asymmetric effects of the reform on the equilibrium rates of low risk and high risk loans should not be read as a reflection of distortions introduced by Basel II. Rather, they reflect the correction of (possibly more worrying) distortions that prevailed under Basel I. A reform that allows banks to save capital on low risk loans may be justified if the previous regulation could not discriminate between different classes of loans and was conservatively targeted to guarantee a minimum degree of

\footnotetext{
${ }^{18}$ If intermediation costs like those in Appendix B made banks non-specialized, then banks with a higher proportion of low risk (high risk) loans would adopt the IRB (standardized) approach of Basel II, so Proposition 3 would still hold.
} 
solvency for banks specialized in riskier loans. According to this view, the main defect of Basel I would have been the excessive capital charges (and consequently excessively high interest rates) on low risk loans.

An interesting implication of Proposition 3 is the increase in the probability of failure of the banks specialized in low risk lending, $\operatorname{Pr}\left(p_{l}>\widehat{p}_{l}\right)=1-F_{l}\left(\widehat{p}_{l}\right)$. To see this, notice that, by (12), the bankruptcy default rate $\widehat{p}_{l}$ is increasing in the capital requirement $k_{l}$ and the loan rate $r_{l}$. Since $k_{l}^{\mathrm{IRB}}<k^{\mathrm{I}}$ and $r_{l}^{\mathrm{IRB}}<r_{l}^{\mathrm{I}}$, the result follows. Intuitively, after adopting the IRB approach, these banks will have a lower capital buffer and will charge lower rates, so the net interest income earned on performing loans will also be lower. Both effects imply a higher probability of failure. ${ }^{19}$

\subsection{Quantitative effects}

In order to assess the quantitative importance of our results, we now consider a realistic parameterization of the model. In particular, we look at the equilibrium pricing under Basel I and the IRB approach of Basel II of various classes of uncollateralized corporate loans that differ in their PDs, and we compute the levels of bank solvency to which they lead, measured by the probability of failure of banks specialized in each of them.

The reference economy we consider is characterized by the parameters for corporate loans with one year maturity set in Basel II, which are a LGD $\lambda=0.45$ and an exposure to the systematic risk factor which is decreasing in the PD according to the function

$$
\rho\left(\bar{p}_{j}\right)=0.12\left(2-\frac{1-\exp \left(-50 \times \bar{p}_{j}\right)}{1-\exp (-50)}\right),
$$

so that $\rho(0)=0.24$ and $\rho(1)=0.12$. In addition, we set the cost of bank capital $\delta$ equal to $10 \%$.

For this economy, and for PDs $\bar{p}_{j}$ in a range from $0.03 \%$ (which is the minimum

\footnotetext{
${ }^{19}$ Notice that despite the reduction in the solvency of the banks specialized in low risk lending, the simulations below show that Basel II will keep them safer than the banks specialized in high risk lending that adopt the standardized approach.
} 
contemplated in Basel II) to $10 \%$, we compute the equilibrium loan rates, $r_{j}^{*}$, and the probabilities of bank failure, $\operatorname{Pr}\left(p_{j}>\widehat{p}_{j}\right)=1-F_{j}\left(\widehat{p}_{j}\right)$, under two different capital requirements. The first one corresponds to Basel I (or the standardized approach of Basel II for unrated corporate loans) so that $k_{j}^{\mathrm{I}}=8 \%$. The second one corresponds to the IRB formula (8) for corporate loans with maturity of one year, with $\lambda=0.45$, $\alpha=0.999$, and $\rho\left(\bar{p}_{j}\right)$ given by (14). The results are shown in Table 1.

Table 1

Quantitative effects of Basel II

(all variables in per cent)

\begin{tabular}{rccccc}
\hline & \multicolumn{2}{c}{ Loan rates } & & \multicolumn{2}{c}{ Failure probabilities } \\
\cline { 2 - 3 } \cline { 5 - 6 } $\bar{p}_{j}$ & $\begin{array}{c}\text { Basel I or } \\
\text { Standardized }\end{array}$ & IRB & & $\begin{array}{c}\text { Basel I or } \\
\text { Standardized }\end{array}$ & IRB \\
\hline 0.03 & 0.81 & 0.08 & & 0.00 & 0.08 \\
0.05 & 0.82 & 0.11 & & 0.00 & 0.07 \\
0.10 & 0.85 & 0.20 & & 0.00 & 0.07 \\
0.20 & 0.89 & 0.34 & & 0.00 & 0.07 \\
0.50 & 1.03 & 0.67 & & 0.00 & 0.06 \\
1.00 & 1.26 & 1.09 & & 0.02 & 0.05 \\
2.00 & 1.73 & 1.79 & & 0.06 & 0.04 \\
4.00 & 2.70 & 3.07 & & 0.23 & 0.03 \\
7.00 & 4.23 & 5.03 & & 0.85 & 0.02 \\
10.00 & 5.83 & 7.06 & & 2.01 & 0.01 \\
\hline
\end{tabular}

Since we have normalized to zero the interest rate on (fully insured) deposits, the interest rates in Table 1 should be interpreted as spreads over a risk-free rate. ${ }^{20}$ Moreover, these spreads do not incorporate any component of intermediation or origination costs, since we have assumed them to be zero.

For PDs of about $2 \%$, the two regulations imply very similar capital charges and hence very similar loan rates. Yet, as stated in Proposition 2, loan rates are more

\footnotetext{
${ }^{20}$ In reality there could be a positive spread between the risk-free rate and the deposit rate, reflecting either monopolistic rents in the deposit market or charges due to the costs of the liquidity and payment services associated with deposits. Yet, if there is a (collateralized) interbank market, then under certain conditions banks' deposit taking and lending activities would be separable, and the interbank repo rate would be the appropriate reference rate for the pricing of bank loans.
} 
sensitive to PDs under IRB capital requirements than under Basel I requirements, so for smaller (larger) PDs the rates implied by the former are smaller (larger) than those implied by the latter. Our analysis identifies two reasons for this different behavior. First and foremost, IRB capital requirements are increasing in the PD and banks pass the corresponding additional financing cost on to the borrowers in the form of higher loan rates. Second, under Basel I the probability of bank failure and hence the implied deposit insurance subsidy is increasing in the PD, and under perfect competition banks transfer it to the borrowers in the form of lower rates, partly offsetting the direct positive effect of PDs on loan rates.

According to Table 1, adopting the IRB approach may imply a reduction in loan rates of 65 basis points for loans with a $\mathrm{PD}$ of $0.10 \%$, and an increase of about 125 basis points for loans with a PD of $10 \%$. These numbers illustrate the quantitative significance of the interest rate savings that, as predicted by Proposition 3, will make low risk (high risk) firms prefer to borrow from banks that adopt the IRB (standardized) approach of Basel II.

The flat $8 \%$ capital requirement of Basel I translates into a probability of failure of virtually zero for banks specialized in low PD loans, while it leads to a significantly positive probability for banks specialized in high PD loans. On the other hand, it is interesting to note that the probabilities of bank failure under the IRB approach are lower than the benchmark of $0.1 \%$ associated with the confidence level of $99.9 \%$.

To explain this result, observe that by the definition (12) of the bankruptcy default rate $\widehat{p}_{j}$, together with the fact that $r_{j}^{*}>0$, we have

$$
\widehat{p}_{j}=\frac{\lambda p_{j}\left(z_{\alpha}\right)+r_{j}^{*}}{\lambda+r_{j}^{*}}>p_{j}\left(z_{\alpha}\right),
$$

which implies that the actual solvency probability implied by the IRB formula is greater than the target confidence level $\alpha$, that is, $F_{j}\left(\widehat{p}_{j}\right)>\alpha$. This is due to the fact that the net interest income earned on performing loans (partially) covers the losses incurred on defaulting loans, an effect that is not taken into account in the construction of the IRB capital requirement. This effect is more significant when 
loan rates are high, which explains why in Table 1 the banks specialized in riskier loans exhibit lower probabilities of failure.

\subsection{A net interest income correction}

Correcting the excessive capital charges for high risk loans implied by the IRB approach of Basel II is straightforward. It simply requires deducting the net interest income of non-defaulting loans from the losses associated with defaulting loans. In particular, one could require banks with loans of class $j$ to hold a minimum capital $k_{j}$ such that their net worth is positive with a target confidence level $\alpha$, that is, $F_{j}\left(\widehat{p}_{j}\right)=\alpha$ or, equivalently, $\widehat{p}_{j}=F_{j}^{-1}(\alpha)=p_{j}\left(z_{\alpha}\right)$. Using the definition (12) of $\widehat{p}_{j}$ then gives

$$
k_{j}=\lambda p_{j}\left(z_{\alpha}\right)-r_{j}^{*}\left[1-p_{j}\left(z_{\alpha}\right)\right] .
$$

The first term in (15) is the IRB capital requirement of Basel II, and the second is the appropriate net interest income correction. This correction is based on the $\alpha$-quantile of the distribution of the default rate, $p_{j}\left(z_{\alpha}\right)$, because what matters for ensuring solvency with a confidence level $\alpha$ is the net interest income when no more than such a fraction of loans default.

Since the equilibrium loan rate $r_{j}^{*}$ depends on the capital requirement $k_{j}$, obtaining a closed-form expression for $k_{j}$ requires solving simultaneously (15) and the zero net value condition $V_{j}=0$. Integrating by parts in (11) and using the fact that the integrand is zero for $p_{j}=\widehat{p}_{j}$, we can rewrite this condition as

$$
V_{j}=-k_{j}+\frac{\lambda+r_{j}^{*}}{1+\delta} \int_{0}^{\widehat{p}_{j}} F_{j}\left(p_{j}\right) d p_{j}=0
$$

Solving for $r_{j}^{*}$ in (16), substituting the resulting expression in (15), and using the fact that by construction $\widehat{p}_{j}=p_{j}\left(z_{\alpha}\right)$, gives the following explicit formula for the corrected IRB capital requirement

$$
k_{j}=\frac{\lambda \int_{0}^{p_{j}\left(z_{\alpha}\right)} F_{j}\left(p_{j}\right) d p_{j}}{(1+\delta)\left[1-p_{j}\left(z_{\alpha}\right)\right]+\int_{0}^{p_{j}\left(z_{\alpha}\right)} F_{j}\left(p_{j}\right) d p_{j}} .
$$


In order to avoid the numerical computation of the integral in (17), we can obtain an approximation to the proposed $k_{j}$ by noting that for $p_{j}>p_{j}\left(z_{\alpha}\right)$ we have $F_{j}\left(p_{j}\right)>F_{j}\left(p_{j}\left(z_{\alpha}\right)\right)=\alpha$. Thus for values of the confidence level $\alpha$ close to 1 , we have $\int_{p_{j}\left(z_{\alpha}\right)}^{1} F_{j}\left(p_{j}\right) d p_{j} \simeq 1-p_{j}\left(z_{\alpha}\right)$, so we can write

$$
\int_{0}^{p_{j}\left(z_{\alpha}\right)} F_{j}\left(p_{j}\right) d p_{j}=\int_{0}^{1} F_{j}\left(p_{j}\right) d p_{j}-\int_{p_{j}\left(z_{\alpha}\right)}^{1} F_{j}\left(p_{j}\right) d p_{j} \simeq p_{j}\left(z_{\alpha}\right)-\bar{p}_{j} .
$$

Substituting this approximation into (17) then gives

$$
k_{j} \simeq \frac{\lambda\left[p_{j}\left(z_{\alpha}\right)-\bar{p}_{j}\right]}{\delta\left[1-p_{j}\left(z_{\alpha}\right)\right]+1-\bar{p}_{j}} .
$$

The same approximation can be obtained from (15) if the equilibrium loan rate $r_{j}^{*}$ is replaced by the actuarially fair rate $\bar{r}_{j}$ defined in (13). This is just a consequence of the fact that, as shown in Appendix A, for high values of the confidence level $\alpha$, the equilibrium and the fair rates are almost identical.

\section{Table 2}

Net interest income correction of IRB requirements (all variables in per cent)

\begin{tabular}{cccccc}
\hline & \multicolumn{2}{c}{ Capital charges } & & \multicolumn{2}{c}{ Loan rates } \\
\cline { 2 - 3 } \cline { 5 - 6 } $\bar{p}_{j}$ & Original & Corrected & & Original & Corrected \\
\hline 0.03 & 0.62 & 0.55 & & 0.08 & 0.07 \\
0.05 & 0.92 & 0.82 & & 0.11 & 0.10 \\
0.10 & 1.54 & 1.36 & & 0.20 & 0.18 \\
0.20 & 2.49 & 2.20 & & 0.34 & 0.31 \\
0.50 & 4.40 & 3.85 & & 0.67 & 0.61 \\
1.00 & 6.31 & 5.45 & & 1.09 & 1.00 \\
2.00 & 8.56 & 7.22 & & 1.79 & 1.65 \\
4.00 & 11.51 & 9.39 & & 3.07 & 2.85 \\
7.00 & 15.24 & 12.14 & & 5.03 & 4.69 \\
10.00 & 18.56 & 14.66 & & 7.06 & 6.63 \\
\hline
\end{tabular}

Simulations parallel to those described above, which are summarized in Table 2, reveal that the net interest income correction leads to a reduction of the IRB capital 
requirement of almost 1 percentage point for a $\mathrm{PD}$ of $1 \%$ and almost 4 percentage points for a $\mathrm{PD}$ of $10 \%$. The resulting impact on equilibrium loan rates (relative to the rates obtained under the original IRB requirements) is very small for low risk loans, but raises up to about 40 basis points for loans with a PD of $10 \%$.

Interestingly, the corrected IRB requirement (17), as well as its approximation (18), is decreasing in the cost of capital $\delta$. This is explained by the fact that, under perfect competition, a higher cost of capital is borne by the borrowers in the form of higher loan rates, which add to the net interest income buffer. Thus, in contrast with the invariance of the original IRB requirements, market conditions that lead to a higher cost of capital, such as imperfect capital markets or economic recessions, will ceteris paribus lower the corrected IRB requirements - a consideration that can be relevant for the discussions on procyclicality.

\section{Optimal Capital Requirements}

Requiring banks to hold capital increases their funding costs. Under perfect competition, these additional costs are transferred to the borrowers in the form of higher loan rates. To justify this social cost of regulation one needs to introduce some social benefit, for example in the form of a reduction in the probability (and hence the expected cost) of bank failures. In what follows we assume that the failure of a bank entails a social cost $s>0$ per unit of loans. We consider a regulatory system that allows to impose a different capital requirement $k_{j}$ to each loan class $j$, and we compute the level of the cost $s$ for which the IRB requirement of Basel II would be optimal.

\subsection{A social welfare function}

In our risk-neutral economy, social welfare may be evaluated by simply adding the expected payoffs of the four classes of agents: entrepreneurs, bankers, depositors, and the government. For convenience, we will express these payoffs in $t=1$ terms. Since bankers and depositors get expected returns that just cover the opportunity cost of 
their funds, their net expected payoffs are zero.

The entrepreneurs of each class $j$ appropriate their firms' returns in excess of equilibrium loan repayments in the event of success, $a-r_{j}^{*}$, and get zero in the event of failure, so their expected payoff is

$$
U_{j}=\left(1-\bar{p}_{j}\right)\left[(1+a)-\left(1+r_{j}^{*}\right)\right]=\left(1-\bar{p}_{j}\right)\left(a-r_{j}^{*}\right)
$$

The corresponding expected payoff of the government is

$$
G_{j}=E\left[\min \left\{\pi_{j}(z), 0\right\}\right]-s\left[1-F_{j}\left(\widehat{p}_{j}\right)\right]
$$

where the first term is the liability that a bank of size one specialized in lending to firms of class $j$ imposes on the deposit insurance system (the expected value of the negative part of the bank's net worth), while the second is the expected social cost of bank failure ( $s$ times the corresponding probability). Using the properties of the $\min \left\{\pi_{j}(z), 0\right\}$ function and the definition $(10)$ of $\pi_{j}(z)$, the first term can be written as

$$
E\left[\pi_{j}(z)-\max \left\{\pi_{j}(z), 0\right\}\right]=k_{j}+r_{j}^{*}-\bar{p}_{j}\left(\lambda+r_{j}^{*}\right)-E\left[\max \left\{\pi_{j}(z), 0\right\}\right] .
$$

But the bank's zero net value condition implies that, in equilibrium, $E\left[\max \left\{\pi_{j}(z), 0\right\}\right]=$ $(1+\delta) k_{j}$, so we can simply write

$$
G_{j}=\left(1-\bar{p}_{j}\right) r_{j}^{*}-\bar{p}_{j} \lambda-\delta k_{j}-s\left[1-F_{j}\left(\widehat{p}_{j}\right)\right]
$$

Social welfare is measured by the sum of the expected payoffs of the entrepreneurs and the government, and it is clear that it can be additively decomposed into the contribution from each class of firms. Using (19) and (20), we can express the contribution per unit of loans to firms of class $j$ as

$$
W_{j}=U_{j}+G_{j}=\left(1-\bar{p}_{j}\right) a-\bar{p}_{j} \lambda-\delta k_{j}-s\left[1-F_{j}\left(\widehat{p}_{j}\right)\right],
$$

that is, the expected net returns of firms' projects, $\left(1-\bar{p}_{j}\right) a-\bar{p}_{j} \lambda$, minus the cost of the capital required by their loans, $\delta k_{j}$, minus the expected social cost of the corresponding bank failures, $s\left[1-F_{j}\left(\widehat{p}_{j}\right)\right]$. 
The optimal capital requirement for each loan class $j$ can be obtained by maximizing (21) with respect to $k_{j}$. An interior solution is characterized by the first order condition

$$
s F_{j}^{\prime}\left(\widehat{p}_{j}\right) \frac{d \widehat{p}_{j}}{d k_{j}}=\delta
$$

where $F_{j}^{\prime}\left(\widehat{p}_{j}\right)$ is positive since it is the density function of the default rate $p_{j}$, and from (12) we have

$$
\frac{d \widehat{p}_{j}}{d k_{j}}=\frac{1}{\lambda+r_{j}^{*}}\left[1+\left(1-\widehat{p}_{j}\right) \frac{\partial r_{j}^{*}}{\partial k_{j}}\right],
$$

which is also positive since $\partial r_{j}^{*} / \partial k_{j}>0$ by Proposition 1. Condition (22) simply equates the marginal social benefit of bank capital (increasing $k_{j}$ increases the bankruptcy default rate $\widehat{p}_{j}$ both directly and through $r_{j}^{*}$, and thus reduces the probability of bank failure) to its marginal cost (increasing $k_{j}$ increases the cost of financing firms' projects).

\subsection{Quantifying the trade-off}

Condition (22) implicitly defines the level of the social cost of bank failure $s$ for which any given capital requirement $k_{j}$ would be optimal. ${ }^{21}$ Table 3 shows this implicit social cost for the economy considered in Section 4.2 and the two IRB capital requirements already used in Table 2: the original requirement for corporate loans with maturity of one year and its correction for net interest income.

Table 3 shows that the social cost of bank failure implicit in the IRB capital requirements of Basel II is remarkably increasing in the PD. While it is moderate for low PDs, it becomes implausibly large for PDs above 0.5\%, exceeding several times the size of the bank's balance sheet, which suggests that IRB capital charges are too high. ${ }^{22}$ Correcting for net interest income reduces significantly the implicit social cost, but the steep increase with the PD is troubling.

\footnotetext{
${ }^{21}$ Obviously, one needs to check that the solution corresponds to a maximum.

${ }^{22}$ Notice, however, that this problem may have little practical incidence if high PD firms turn to banks that adopt the standardized approach of Basel II.
} 
Table 3

Implicit social cost of bank failure (all variables in per cent)

\begin{tabular}{rrc}
\hline $\bar{p}_{j}$ & Original IRB & Corrected IRB \\
\hline 0.03 & 33.89 & 23.94 \\
0.05 & 48.35 & 33.48 \\
0.10 & 76.43 & 51.16 \\
0.20 & 116.57 & 74.69 \\
0.50 & 190.82 & 111.43 \\
1.00 & 265.17 & 136.65 \\
2.00 & 373.40 & 153.77 \\
4.00 & 592.58 & 168.21 \\
7.00 & 964.57 & 189.09 \\
10.00 & 1346.49 & 207.45 \\
\hline
\end{tabular}

To interpret these results, notice that by (22) the implicit social cost of bank failure is inversely proportional to the marginal reduction in the probability of bank failure that can achieved by increasing $k_{j}$ at the required levels of capital. It turns out that, with the confidence levels of Basel II, the marginal effect of $k_{j}$ on bank solvency is tiny for high PDs, and only a huge social cost $s$ may justify the size of these capital requirements.

The striking results in Table 3 are explained by the fact that both the original and the corrected capital requirements are based on a purely statistical criterion, namely that capital should cover the gross or the net (of interest income) credit losses with a given confidence level $\alpha$. By construction, such a criterion is not justified in terms of explicit costs and benefits, which means that the same confidence level may imply very different economic trade-offs across loan risk classes. Moreover, the criterion is independent of relevant parameters such as the cost of bank equity capital, which may not be the constant over time and across countries.

These results suggest that it would be desirable to base the discussion on the design of capital requirements on explicit economic trade-offs. Our preceding analysis is just a first attempt since issues such as moral hazard, bank panics, and contagion might require a treatment that goes beyond introducing a reduced-form cost of bank failure. 


\section{Discussion}

In this section we comment on two simple extensions that expand the set of predictions that can be derived from our analysis and, after proper calibration, would allow a finer quantification of the effects of Basel II.

\subsection{Bank lending}

Assuming that the demand for each class of loans is inelastic implies that changes in regulation only have an effect on loan rates, leaving the volume and composition of lending unchanged. Implications for quantities could be easily derived by introducing heterogeneity in entrepreneurs' reservation utilities. Specifically, if we let $m_{j}\left(U_{j}\right)$ denote the measure of potentially borrowing entrepreneurs of class $j$ whose reservation utility is less than or equal to $U_{j}$, then the market demand for loans of class $j$ is given by $L_{j}\left(r_{j}^{*}\right)=m_{j}\left(\left(1-\bar{p}_{j}\right)\left(a-r_{j}^{*}\right)\right)$, because only the entrepreneurs with reservation utilities below the expected payoff $U_{j}^{*}=\left(1-\bar{p}_{j}\right)\left(a-r_{j}^{*}\right)$ in (19) will want to undertake their projects. Since $L_{j}\left(r_{j}^{*}\right)$ is decreasing, it follows that changes in parameters that affect the equilibrium loan rate $r_{j}^{*}$ will produce variations of the opposite sign in the corresponding volume of lending. ${ }^{23}$ Accordingly, by Proposition 1, under Basel I (or the standardized approach of Basel II) equilibrium lending will be decreasing in the PD and the LGD of the corresponding class of loans, as well as in the capital requirement and the cost of capital. And, by Proposition 3, moving to Basel II will increase the volume of low risk lending, leaving high risk lending unchanged.

\subsection{Cost of capital and procyclicality}

Taking the cost of bank capital $\delta$ as an exogenous parameter is equivalent to assuming a perfectly elastic supply of bank capital at such rate. In this context, shocks to the different parameters of the model may induce fluctuations in the aggregate demand for bank capital but there are no feedback effects on loan rates (or loan volumes).

\footnotetext{
${ }^{23}$ Quantitatively, the importance of these effects would depend on the elasticity of the demand for loans, which would be proportional to the density of entrepreneurs at the reservation utility $U_{j}^{*}$.
} 
Yet, these feedback effects are a great concern in the discussions on the potential procyclicality of Basel II. ${ }^{24}$ A simple way to accommodate them is to introduce an increasing supply of bank capital, $K(\delta)$. With inelastic demands for each class of loans, the aggregate demand for bank capital is simply $l k_{l}+(1-l) k_{h}$, where $l$ denotes the proportion of low risk firms. The equilibrium cost of capital $\delta^{*}$ is then determined by the market clearing condition $K\left(\delta^{*}\right)=l k_{l}+(1-l) k_{h}$, and its variations recursively affect the pricing of bank loans according to the results in Proposition $1 .^{25}$

Thus, under Basel I (or the standardized approach of Basel II), the cost of capital would be increasing in the capital requirement and decreasing in the shocks to the supply of bank capital, inducing variations of the same sign in loan rates. And under the IRB approach of Basel II, the cost of capital would be decreasing in the shocks to the supply of bank capital and increasing in the confidence level $\alpha$. In this setting, if there is a positive correlation between the factors that stimulate aggregate economic activity and bank capital, and a negative correlation between these factors and capital requirements, then (unless there is a fully offsetting cyclical pattern in the demand for loans) the cost of bank capital would tend to be high in recessions and low in expansions. Obviously, moving to Basel II may exacerbate this procyclicality since its capital requirements are more sensitive to risk than those of Basel I. ${ }^{26}$ On the other hand, according to Proposition 3, Basel II may reduce the overall demand for bank capital and, consequently, its cost, leading to lower average rates for both high and low risk firms.

\footnotetext{
${ }^{24}$ See, for example, Lowe (2002).

${ }^{25}$ With elastic loan demands, the recursivity of the system breaks down. An increase in $\delta$ increases the rates applied to each class of loans. If, consequently, the demand for loans decreases, so does the capital required by banks, introducing a further equilibrating force in the market for bank capital. Clearly, this mechanism would imply translating part of the adjustment to the equilibrium volumes of lending.

${ }^{26}$ Notice that our net interest income correction would partly compensate this effect, since the resulting IRB requirements are less sensitive to risk and also decreasing in the cost of capital.
} 


\section{Concluding Remarks}

We have analyzed the loan pricing implications of capital requirements in a credit market where, as in the model underlying the internal ratings based (IRB) approach of Basel II, loan default rates are driven by a single factor of systematic risk. We have focused on the effects of the transition from Basel I, with a common capital charge for all business loans, to Basel II, which allows banks to choose between a standardized approach (which treats all loans to unrated firms essentially as in Basel I) and an IRB approach (which makes capital charges a function of the bank's estimate of the $\mathrm{PD})$.

The relatively advantageous (disadvantageous) treatment that low risk (high risk) lending receives in the IRB approach implies that banks specializing in low risk (high risk) lending will tend to adopt the IRB (standardized) approach. Accordingly, the equilibrium rates of low risk loans will be lower than under Basel I, while the equilibrium rates of high risk loans will be roughly the same as under Basel I. For the same reason, one might expect that the non-specialized banks that adopt the IRB approach will now have an incentive to securitize their high risk portfolios.

We have computed the level of the social cost of bank failure that could justify the IRB capital requirements of Basel II. The implausibly large size of this cost suggests that the current design implies too high charges, especially for riskier loans. The result is partly due to the fact that Basel II does not take into account the net interest income from performing loans, which provides a buffer, in addition to capital, against credit losses. We have derived a simple closed-form formula that incorporates a net interest income correction in IRB capital requirements.

An interesting quantitative finding (confirmed by the result in Appendix A) is that, with the levels of solvency implied by the IRB approach of Basel II, the deposit insurance subsidy is very small, and hence has a negligible effect on loan pricing. ${ }^{27}$

\footnotetext{
${ }^{27}$ This also implies that the actuarially fair deposit insurance premia for banks adopting the IRB approach would be very small.
} 
This is also the case under Basel I for banks with relatively safe portfolios, which is somewhat surprising in view of the vast literature on the risk-shifting effects of deposit insurance. In our economy, the distortions to the allocation of credit that such subsidy may cause are virtually zero (actually, they are replaced by distortions of an opposite sign due to the cost of bank capital). Of course, IRB requirements rely quite crucially on attributing to each loan an unbiased estimate of its PD. Our results suggest that the literature on moral hazard in banking should now focus on the incentives for banks to properly estimate and truthfully report the risk of their loans, that is, on the system of penalties and/or rewards that would ensure compliance. This is precisely the subject of the supervisory review process (or Pillar 2) of Basel II, whose analysis by academics has only started. ${ }^{28}$

${ }^{28}$ See Decamps et al. (2004). 


\section{Appendices}

\section{A Equilibrium and actuarially fair rates}

This appendix shows that the difference between the actuarially fair rate $\bar{r}_{j}$ and the equilibrium loan rate $r_{j}^{*}$ satisfies

$$
0<\bar{r}_{j}-r_{j}^{*}<\frac{\left(\lambda-k_{j}\right)\left[1-F_{j}\left(\widehat{p}_{j}\right)\right]}{\left(1-\bar{p}_{j}\right)} .
$$

To prove this, notice that the fact that $\max \{\pi, 0\}=\pi-\min \{\pi, 0\}$ allows us to rewrite the zero net value condition $V_{j}=0$ as

$$
-k_{j}+\frac{1}{1+\delta} E\left[k_{j}+r_{j}^{*}-p_{j}\left(\lambda+r_{j}^{*}\right)\right]-\frac{1}{1+\delta} E\left[\min \left\{k_{j}+r_{j}^{*}-p_{j}\left(\lambda+r_{j}^{*}\right), 0\right\}\right]=0,
$$

which, multiplying by $1+\delta$ and reordering, implies

$$
\left(1-\bar{p}_{j}\right) r_{j}^{*}-\bar{p}_{j} \lambda-\delta k_{j}=E\left[\min \left\{k_{j}+r_{j}^{*}-p_{j}\left(\lambda+r_{j}^{*}\right), 0\right\}\right]<0
$$

On the other hand, integrating by parts, and using the definition (12) of $\widehat{p}_{j}$ we have

$$
\begin{aligned}
E\left[\min \left\{k_{j}+r_{j}^{*}-p_{j}\left(\lambda+r_{j}^{*}\right), 0\right\}\right] & =k_{j}-\lambda+\left(\lambda+r_{j}^{*}\right) \int_{\widehat{p}_{j}}^{1} F_{j}\left(p_{j}\right) d p_{j} \\
& >k_{j}-\lambda+\left(\lambda+r_{j}^{*}\right)\left(1-\widehat{p}_{j}\right) F_{j}\left(\widehat{p}_{j}\right) \\
& =\left(k_{j}-\lambda\right)\left[1-F_{j}\left(\widehat{p}_{j}\right)\right] .
\end{aligned}
$$

Putting together the two inequalities implies

$$
\left(k_{j}-\lambda\right)\left[1-F_{j}\left(\widehat{p}_{j}\right)\right]<\left(1-\bar{p}_{j}\right) r_{j}^{*}-\bar{p}_{j} \lambda-\delta k_{j}<0,
$$

which, given the definition (13) of the actuarially fair rate $\bar{r}_{j}$, proves the result.

Computing the upper bound in (23) requires knowledge of the bankruptcy default rate $\widehat{p}_{j}$ and hence the equilibrium rate $r_{j}^{*}$. An alternative less tight bound can be derived by noting that $\widehat{p}_{j}>k_{j} / \lambda$ so

$$
\bar{r}_{j}-r_{j}^{*}<\frac{\left(\lambda-k_{j}\right)\left[1-F_{j}\left(k_{j} / \lambda\right)\right]}{\left(1-\bar{p}_{j}\right)} .
$$


Moreover, in the IRB approach we have $k_{j}=\lambda p_{j}\left(z_{\alpha}\right)$, so $F_{j}\left(k_{j} / \lambda\right)=F_{j}\left(p_{j}\left(z_{\alpha}\right)\right)=\alpha$, so using $p_{j}\left(z_{\alpha}\right)>\bar{p}_{j}$ the upper bound further simplifies to

$$
\bar{r}_{j}-r_{j}^{*}<\frac{\lambda\left[1-p_{j}\left(z_{\alpha}\right)\right](1-\alpha)}{\left(1-\bar{p}_{j}\right)}<\lambda(1-\alpha) .
$$

The positive difference between $\bar{r}_{j}$ and $r_{j}^{*}$ is due to the fact that, under perfect competition, the deposit insurance subsidy is transferred to the borrowers in the form of lower equilibrium rates. The upper bounds in (23) and (24) provide approximations to the pricing error incurred if this effect is ignored. For most values of the failure probability $1-F_{j}\left(\widehat{p}_{j}\right)$ in Table 1 , the upper bound in $(23)$ is very small. In the Basel I case, this bound is effectively zero for low PDs. In the IRB case, as clearly shown by (24), the confidence level of $99.9 \%$ also implies a tiny difference between $\bar{r}_{j}$ and $r_{j}^{*}$.

\section{B The case of non-specialized banks}

This appendix extends our results to the case where the bank's portfolio problem has an interior solution. We first relax the assumption of zero intermediation costs, and show how the presence of complementarities in the bank's cost function may counterbalance the convexity that limited liability introduces in the bank's objective function. Then, assuming that the bank makes both classes of loans, we show that the comparative statics summarized in Proposition 1 still hold.

Let $C(L, H)$ denote the intermediation costs that a representative bank incurs at $t=0$ when it lends an amount $L$ to low risk firms and an amount $H$ to high risk firms. Assume that $C(L, H)$ is linearly homogeneous, increasing, and convex. By homogeneity we can write $C(L, H)=(L+H) c(\gamma)$, where $c(\gamma)$ is a function of the ratio $\gamma \equiv L /(L+H)$. In this case, the marginal costs of low risk and high risk lending satisfy

$$
\begin{aligned}
& C_{l}(\gamma)=\frac{\partial C(L, H)}{\partial L}=c(\gamma)+(1-\gamma) c^{\prime}(\gamma) \\
& C_{h}(\gamma)=\frac{\partial C(L, H)}{\partial H}=c(\gamma)-\gamma c^{\prime}(\gamma),
\end{aligned}
$$


which imply

$$
c(\gamma)=\gamma C_{l}(\gamma)+(1-\gamma) C_{h}(\gamma) \quad \text { and } \quad c^{\prime}(\gamma)=C_{l}(\gamma)-C_{h}(\gamma)
$$

Also, the convexity of $C(L, H)$ implies $c^{\prime \prime}(\gamma)>0$.

For a loan portfolio of size one (that is, $L+H=1$ ), the objective function of the representative bank becomes

$$
V(\gamma)=-\left[\gamma k_{l}+(1-\gamma) k_{h}\right]-c(\gamma)+\frac{1}{1+\delta} \int_{-\infty}^{\widehat{z}}\left[\gamma \pi_{l}(z)+(1-\gamma) \pi_{h}(z)\right] d \Phi(z),
$$

where the critical value $\widehat{z}$ is implicitly defined by

$$
\gamma \pi_{l}(\widehat{z})+(1-\gamma) \pi_{h}(\widehat{z})=0
$$

The first term in (25) is linear in $\gamma$, the second is concave (since $c^{\prime \prime}(\gamma)>0$ ), and the third is convex (see the proof of Lemma 1). Hence we may have corner solutions (like in the model with zero intermediation costs) or interior solutions. In what follows, we assume that the concavity of the intermediation cost term dominates and there is an interior solution characterized by the first order condition

$$
V^{\prime}(\gamma)=\left(k_{h}-k_{l}\right)-c^{\prime}(\gamma)+\frac{1}{1+\delta} \int_{-\infty}^{\widehat{z}}\left[\pi_{l}(z)-\pi_{h}(z)\right] d \Phi(z)=0
$$

In this situation, a competitive equilibrium would be characterized by (27) together with the zero net value condition, $V(\gamma)=0$, and the market clearing condition that equates the supply of low risk loans, $\gamma$, to the proportion of low risk firms in the economy, denoted by $l$. Let us define

$$
V_{j}^{\prime}=-k_{j}-C_{j}(l)+\frac{1}{1+\delta} \int_{-\infty}^{\widehat{z}} \pi_{j}(z) d \Phi(z),
$$

for $j=l, h$. Substituting $c^{\prime}(\gamma)=C_{l}(\gamma)-C_{h}(\gamma)$ into $(27)$, setting $\gamma=l$, and rearranging gives $V_{l}^{\prime}=V_{h}^{\prime}$, and substituting $c(\gamma)=\gamma C_{l}(\gamma)+(1-\gamma) C_{h}(\gamma)$ into $(27)$, setting $\gamma=l$, and rearranging gives $\gamma V_{l}^{\prime}+(1-\gamma) V_{h}^{\prime}=0$. These two equations imply $V_{j}^{\prime}=0$, for $j=l, h$, which one can take as the loan pricing equations for the non-specialization case. 
The new loan pricing equation for loans of class $j$ is identical to that of the specialization case, except for the fact that (i) it includes the marginal cost term $C_{j}(l)$, and (ii) the critical value $\widehat{z}$ is defined by condition (26) instead of $\pi_{j}(\widehat{z})=0$. Its interpretation is straightforward: the marginal benefit of making one additional loan to a firm of class $j$ must compensate the bank for the required capital and the marginal intermediation cost.

The comparative statics of the equilibrium loan rate $r_{j}^{*}$ may be obtained by differentiating the condition $V_{j}^{\prime}=0$. Specifically, we have

$$
\frac{\partial r_{j}^{*}}{\partial k_{j}}=\frac{1-\frac{1}{1+\delta}\left[\Phi(\widehat{z})+\pi_{j}(\widehat{z}) \Phi^{\prime}(\widehat{z}) \frac{\partial \widehat{z}}{\partial k_{j}}\right]}{\frac{1}{1+\delta}\left[\int_{-\infty}^{\widehat{z}}\left[1-p_{j}(z)\right] d \Phi(z)+\pi_{j}(\widehat{z}) \Phi^{\prime}(\widehat{z}) \frac{\partial \widehat{z}}{\partial r_{j}}\right]}
$$

The problem in signing this expression is that $\pi_{j}(\widehat{z})$ may be positive or negative: we only know that $\pi_{l}(\widehat{z}) \geq 0$ if and only if $\pi_{h}(\widehat{z}) \leq 0$. However, for the confidence levels implicit in the current and the proposed Basel regulation, $\Phi^{\prime}(\widehat{z})$ is very small, so we have

$$
\frac{\partial r_{j}^{*}}{\partial k_{j}} \simeq \frac{1-\frac{1}{1+\delta} \Phi(\widehat{z})}{\frac{1}{1+\delta} \int_{-\infty}^{\widehat{z}}\left[1-p_{j}(z)\right] d \Phi(z)}>0 .
$$

Alternatively, when $\widehat{z} \rightarrow \infty$ the condition $V_{j}^{\prime}=0$ becomes

$$
\left(1-\bar{p}_{j}\right) r_{j}-\bar{p}_{j} \lambda-\delta k_{j}-(1+\delta) C_{j}(l)=0
$$

which, solving for $r_{j}$, yields the actuarially fair rate

$$
\bar{r}_{j}=\frac{\bar{p}_{j} \lambda+\delta k_{j}+(1+\delta) C_{j}(l)}{1-\bar{p}_{j}} .
$$

As in the model with zero intermediation costs, for large $\widehat{z}$ the equilibrium rate $r_{j}^{*}$ is arbitrarily close to $\bar{r}_{j}$, and

$$
\frac{\partial \bar{r}_{j}}{\partial k_{j}}=\frac{\delta}{1-\bar{p}_{j}}>0
$$

so we conclude that $r_{j}^{*}$ must also be increasing in $k_{j}$. The rest of the comparative statics may be obtained in a similar way, replicating the results in Proposition 1. 


\section{Proofs}

Proof of Lemma 1 Substituting the capital requirement (7) into (5), and using the definition (10) of $\pi_{j}(z)$, the bank's objective function (6) can be written as

$$
V(\gamma)=-\left[\gamma k_{l}+(1-\gamma) k_{h}\right]+\frac{1}{1+\delta} E\left[\max \left\{\gamma \pi_{l}(z)+(1-\gamma) \pi_{h}(z), 0\right\}\right]
$$

Now, since $\max \{\pi, 0\}$ is a convex function, while both the expectations operator and the capital requirement are linear, the function $V(\gamma)$ is convex and hence satisfies

$$
V(\gamma) \leq \gamma V(1)+(1-\gamma) V(0) \leq \max \{V(0), V(1)\}
$$

which proves the result.

Proof of Proposition 1 To prove that the zero net value condition (16) has a unique solution that satisfies $0<r_{j}^{*}<\bar{r}_{j}$, observe that for $r_{j}=0$ we have

$$
-k_{j}+\frac{\lambda}{1+\delta} \int_{0}^{\widehat{p}_{j}} F_{j}\left(p_{j}\right) d p_{j}<-k_{j}+\lambda<0
$$

while for $r_{j}=\bar{r}_{j}$, by the definition (13) of the actuarially fair rate $\bar{r}_{j}$ we have

$$
\begin{aligned}
0 & =-k_{j}+\frac{1}{1+\delta} \int_{0}^{1}\left[k_{j}+\bar{r}_{j}-p_{j}\left(\lambda+\bar{r}_{j}\right)\right] d F_{j}\left(p_{j}\right) \\
& <-k_{j}+\frac{1}{1+\delta} \int_{0}^{\widehat{p}_{j}}\left[k_{j}+\bar{r}_{j}-p_{j}\left(\lambda+\bar{r}_{j}\right)\right] d F_{j}\left(p_{j}\right) \\
& =-k_{j}+\frac{\lambda+\bar{r}_{j}}{1+\delta} \int_{0}^{\widehat{p}_{j}} F_{j}\left(p_{j}\right) d p_{j} .
\end{aligned}
$$

Since $V_{j}$ is continuous and increasing in $r_{j}$ the result follows. ${ }^{29}$

Differentiating (16) and using the definitions (4) and (12) of $F_{j}(p)$ and $\widehat{p}_{j}$ gives

$$
\begin{aligned}
& \frac{\partial V_{j}}{\partial r_{j}}=\frac{1}{1+\delta}\left[\frac{\lambda-k_{j}}{\lambda+r_{j}} F_{j}\left(\widehat{p}_{j}\right)+\int_{0}^{\widehat{p}_{j}} F_{j}\left(p_{j}\right) d p_{j}\right]>0, \\
& \frac{\partial V_{j}}{\partial k_{j}}=-1+\frac{1}{1+\delta} F_{j}\left(\widehat{p}_{j}\right)<0,
\end{aligned}
$$

\footnotetext{
${ }^{29}$ Notice that with $k_{j}=0$ we would have $\widehat{p}_{j}>0$, and thus $V_{j}>0$, for all $r_{j}>0$. Hence the zero net value condition (16) could only be satisfied for $r_{j}^{*}=0$. In this case we would have $\widehat{p}_{j}=0$, which would imply that the bank fails with probability one.
} 


$$
\begin{aligned}
& \frac{\partial V_{j}}{\partial \mu_{j}}=-\frac{\lambda+r_{j}}{(1+\delta) \sqrt{\rho}} \int_{0}^{\widehat{p}_{j}} \phi\left(\frac{\sqrt{1-\rho} \Phi^{-1}\left(p_{j}\right)-\mu_{j}}{\sqrt{\rho}}\right) d p_{j}<0, \\
& \frac{\partial V_{j}}{\partial \lambda}=-\frac{1}{1+\delta}\left[\widehat{p}_{j} F_{j}\left(\widehat{p}_{j}\right)-\int_{0}^{\widehat{p}_{j}} F_{j}\left(p_{j}\right) d p_{j}\right]<0, \\
& \frac{\partial V_{j}}{\partial \delta}=-\frac{1}{1+\delta}\left[\frac{\lambda+r_{j}}{1+\delta} \int_{0}^{\widehat{p}_{j}} F_{j}\left(p_{j}\right) d p_{j}\right]=-\frac{1}{1+\delta} k_{j}<0,
\end{aligned}
$$

which implies $\partial r_{j}^{*} / \partial k_{j}>0, \partial r_{j}^{*} / \partial \bar{p}_{j}>0$ (recall that $\left.\bar{p}_{j}=\Phi\left(\mu_{j}\right)\right), \partial r_{j}^{*} / \partial \lambda>0$, and $\partial r_{j}^{*} / \partial \delta>0$. Finally, since an increase in $\rho$ induces a mean-preserving spread on the distribution of $p_{j}$, and the upper bound $\widehat{p}_{j}$ does not depend on $\rho$, the characterization of second-degree stochastic dominance (Rothschild and Stiglitz, 1970) implies

$$
\frac{\partial V_{j}}{\partial \rho}=\frac{\lambda+r_{j}}{1+\delta} \frac{\partial\left[\int_{0}^{\widehat{p}_{j}} F_{j}\left(p_{j}\right) d p_{j}\right]}{\partial \rho}>0
$$

so $\partial r_{j}^{*} / \partial \rho<0$.

Proof of Proposition 2 By the chain rule, the total effect of any parameter $y$ on the equilibrium loan rate $r_{j}^{*}$ is

$$
\frac{d r_{j}^{*}}{d y}=\frac{\partial r_{j}^{*}}{\partial y}+\frac{\partial r_{j}^{*}}{\partial k_{j}} \frac{\partial k_{j}}{\partial y}
$$

where the signs of $\partial r_{j}^{*} / \partial y$ and $\partial r_{j}^{*} / \partial k_{j}$ are obtained from Proposition 1 , and the sign of $\partial k_{j} / \partial y$ from the comparative statics of the IRB capital requirement given by (8). The reference to a sufficiently high confidence level $\alpha$ relates to the fact that $k_{j}$ is increasing in $\rho$ whenever (9) holds.

Proof of Proposition 3 The result follows immediately from the fact that $k_{l}^{\mathrm{IRB}}<$ $k^{\mathrm{S}}=k^{\mathrm{I}}<k_{h}^{\mathrm{IRB}}$. 


\section{References}

[1] Basle Committee on Banking Supervision, 2004. International convergence of capital measurement and capital standards: a revised framework. Basel Committee Publications No. 107.

[2] Bolton, P., Freixas, X., 2000. Equity, bonds, and bank debt: capital structure and financial market equilibrium under asymmetric information. J. Polit. Economy 108, 324-351.

[3] Decamps, J.-P., Rochet, J.-C., Roger, B., 2004. The three pillars of Basel II: optimizing the mix. J. Finan. Intermediation 13, 132-155.

[4] Diamond, D. W., Rajan, R. G., 2000. A theory of bank capital. J. Finance 55, 2431-2465.

[5] Ferguson, R. W., 2003. Concerns and considerations for the practical implementation of the new Basel Accord. Remarks at the ICBI Risk Management Conference, www.federalreserve.gov/boarddocs/speeches/2003/20031202.

[6] Gordy, M. B., 2003. A risk-factor model foundation for ratings-based bank capital rules. J. Finan. Intermediation 12, 199-232.

[7] Hellmann, T. F., Murdock, K. C., Stiglitz, J. E., 2000. Liberalization, moral hazard in banking, and prudential regulation: are capital requirements enough?" Amer. Econ. Rev. 90, 147-165.

[8] Holmström, B., Tirole, J., 1997. Financial intermediation, loanable funds, and the real sector. Quar. J. Econ. 112, 663-691.

[9] Lopez, J., 2004. The empirical relationship between average asset correlation, firm probability of default and asset size. J. Finan. Intermediation 13, 265-283.

[10] Lowe, P., 2002. Credit risk measurement and procyclicality. BIS working paper No. 116. 
[11] Marshall, D. A., Prescott, E. S., 2001. Bank capital regulation with and without state-contingent penalties. Carnegie-Rochester Conf. Ser. Public Pol. 54, 139184 .

[12] Merton, R. C., 1977. An analytic derivation of the cost of deposit insurance and loan guarantees: an application of modern pption pricing theory. J. Banking Finance 1, 3-11.

[13] Rochet, J.-C., 1992. Capital requirements and the behaviour of commercial banks. Europ. Econ. Rev. 36, 1137-1170.

[14] Rothschild, M., Stiglitz, J. E., 1970. Increasing risk I: a definition. J. Econ. Theory 2, 225-243. 